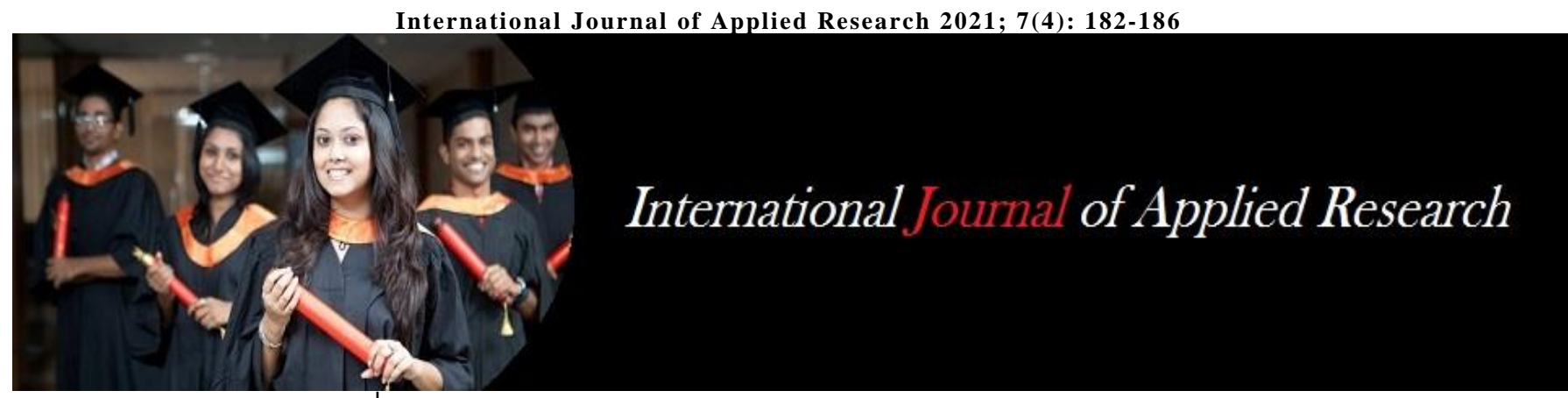

ISSN Print: 2394-7500

ISSN Online: 2394-5869

Impact Factor: 8.4

IJAR 2021; 7(4): 182-186

www.allresearchjournal.com

Received: 20-02-2021

Accepted: 26-03-2021

Dr. Achla Kaushal

Head, Chemical Engineering

Department, Guru Nanak Dev

Institute of Technology,

Rohini, Delhi, India

Dr. M.D. Joshi

Vice-Principal and Faculty in

Polymer Engineering

Department, Guru Nanak Dev

Institute of Technology,

Rohini, Delhi, India
Corresponding Author:

Dr. Achla Kaushal

Head, Chemical Engineering

Department, Guru Nanak Dev

Institute of Technology,

Rohini, Delhi, India

\section{Application of statistical tools in the analysis of adsorption data}

\author{
Dr. Achla Kaushal and Dr. M.D. Joshi
}

DOI: https://doi.org/10.22271/allresearch.2021.v7.i4c.8485

\begin{abstract}
This study was carried out to analyse the experimental data by hypothesis testing using various statistical tests. It enabled us to make significant statements about the adsorption parameters. Dried mango leaf powder was used as an adsorbent to remove $\mathrm{Cu}$ (II), $\mathrm{Zn}$ (II) and $\mathrm{Pb}$ (II) ions from contaminated water samples. Student's t-tests, F-test and Chi-square test and ANOVA were used for the analysis of data. The calculated values of $\mathrm{t}, \mathrm{F}$ and chi-square were compared with their tabulated values listed in literature within 5\% level of significance. Results showed the experimental data in an accepted region on the probability charts, signifying the validity of data $\%$ zinc ions removed, equilibrium time, the effectiveness of adsorption in the removal of zinc ions, equality of variance of two samples of different concentrations and difference of means of multiple samples.
\end{abstract}

Keywords: Statistical analysis, hypothesis testing, probability charts, waste water treatment, adsorption, heavy metals

\section{Introduction}

Adsorption is a known phenomenon in water treatment since ancient times. It is a common phenomenon in the gaseous phase, but is used effectively in the treatment of waste water. Charcoal prepared from wood char, sand and charcoal filters in water purification by Egyptians and Sumerians since $3750 \mathrm{BC}$ are reported in the literature ${ }^{[1,2]}$. During several decades, the concentration of trace heavy metals, synthetic organic chemicals (SOCs) and natural organic materials (NOMs) has increased in water bodies and drinking water supplies to harmful levels. Unlike organic pollutants, heavy metals are known for their toxicity, persistency and non-biodegradability. They find their way into water bodies through industrial, domestic and municipal discharges. Their presence in water is a serious threat to all forms of life because of their mutagenic and carcinogenic nature. Their presence in the body above the prescribed limits can cause severe damages to vital organs of the body, such as kidney, liver, brain, the reproductive system and the nervous system ${ }^{[3]}$.

Of all the methods of waste water treatment, adsorption with agricultural waste is one of the trusted methods in heavy metal removal for its cost effectiveness, availability of wide range of adsorbents and significant efficiency in removing metals from contaminated water. Reseachers have studied adsorbents prepared from agricultural wastes to remove heavy metal ions from polluted water, such as sawdust, tea waste, palm shell, coconut shell, bamboo activated charcoal, olive cake, coir, rice husk etc. ${ }^{[4,5,6]}$. They obtained \%age of heavy metal ions removed w.r.t. adsorbent dose, time, temperature, $\mathrm{pH}$ and metal ion concentration in the sample. This experimental data was analysed by fitting them into non-linear forms such as Langmuir and Freundlich isotherm models.

Various hypothesis tests for the analysis of experimental data are classified as 1) parametric tests, the standard tests, include z-test, t-test, F-test and $\chi^{2}$-test 2) Non-parametric tests, the distribution-free tests of hypotheses, do not dependent on assumptions based on the characteristics of the parent population ${ }^{[7]}$. In this paper, the adsorption process used to remove the metal ions from the contaminated solutions was described qualitatively and quantitatively statistically.

\section{Materials and Method}

Adsorption study of $\mathrm{Zn}$ (II), $\mathrm{Cu}$ (II) and $\mathrm{Pb}$ (II) on mango leaf powder was done batch wise. A stock solution of zinc metal ions was prepared in the lab. 
Analytical grade $\mathrm{Zn}$ metal chips (1 g) dissolved in a few drops of conc. HCl. This concentrated solution was further diluted with distilled water to 1 litre. Stock solutions of copper and lead were also prepared with analytical grade nitrate of the respective metal diluted to 1 litre with distilled water. Stock solutions were further diluted to various concentrations in the range $10-100 \mathrm{mg} / \mathrm{L}$ with the help of distilled water. Mango tree leaves used as adsorbent were collected from the local area were washed, dried and crushed to a size of 200 mesh. The crushed powder was washed thoroughly to remove the colour, dried in a hot air oven for six hours till bone dried and then stored in air tight container. The dried powder was used to determine the $\%$ removal of $\mathrm{Zn}$ (II), $\mathrm{Cu}$ (II) and $\mathrm{Pb}$ (II) ions from the above solutions. 12 Erlenmeyer flasks containing 1-10 g/L mango leaf powder each were used in the 'Orbital' constant temperature variable speed shaker at a time at $20^{\circ} \mathrm{C}$ and 150 rpm for 100 minutes in the $\mathrm{pH}$ range 2-8 to carry out the batch experiment. The solutions were filtered through Whatman filter paper no. 40 after each batch experiment. The concentrations of metal ions in the filtrates were determined by Atomic Absorption Spectrophotometer (CHEMICA 001) using air-acetylene flame. Percentage removal of metal ions from the solutions after the batch experiment was calculated as:

$\%$ Removal $=\left[\left(\mathrm{C}_{\mathrm{i}}-\mathrm{C}_{\mathrm{o}}\right) / \mathrm{C}_{\mathrm{i}}\right]^{*} 100$

(Eq. 6)

Where $\mathrm{C}_{\mathrm{o}}$ denotes the final zinc ion concentration $(\mathrm{mg} / \mathrm{L})$ and $\mathrm{C}_{\mathrm{i}}$ denotes the initial zinc ion concentration in the solution $(\mathrm{mg} / \mathrm{L})$.
Equilibrium adsorption capacity (mg adsorbate/g adsorbent) is calculated as

$\mathrm{q}_{\mathrm{e}}=\left[\left(\mathrm{C}_{\mathrm{i}}-\mathrm{C}_{\mathrm{e}}\right) \mathrm{V}\right] / \mathrm{m}$

Where $\mathrm{V}$ denotes the volume of the solution in litres and $\mathrm{m}$ denotes the mass $(\mathrm{g})$ of the adsorbent used (Kaushal and Singh, 2016 b,c).

\section{Results and Discussion}

Data collected from the experiment was analysed with the help of hypotheses testing within 5\% level of significance.

1. Hypotheses are tested to judge the maximum \% removal of the zinc, copper and lead metal ions from the samples: The samples contained $100 \mathrm{mg} / \mathrm{L}$ of the respective metal ions, an adsorbent dose of $10 \mathrm{~g} / \mathrm{L}$ and different $\mathrm{pH}$ values at $20^{\circ} \mathrm{C}$ was done with two-tailed t-test

Null hypothesis $\mathrm{H}_{\mathrm{o}}: \mu_{\mathrm{Ho}}=$ Maximum \% removal of metal ions from the contaminated sample $=75 \%$ for zinc, $86 \%$ for copper and $79 \%$ for lead.

Alternate hypothesis $\mathrm{H}_{\mathrm{a}}: \mu_{\mathrm{Ho}} \neq 75 \%$ for zinc, $86 \%$ for copper and $79 \%$ for lead.

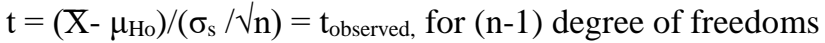
Where $\sigma_{\mathrm{s}}=$ Standard deviation, $\mathrm{X}=$ Average value of $\mathrm{X}$ and $\mathrm{n}=$ sample size.

$\mathrm{Xi}=\%$ removal of metal ions from the contaminated samples.

Average value of $\mathrm{X}=\mathrm{X}=\Sigma \mathrm{X}_{\mathrm{i}} / \mathrm{n}$ and Standard deviation $=\sigma_{\mathrm{s}}$ $=\sqrt{ }\left[\left\{\Sigma\left(\mathrm{X}_{\mathrm{i}}-\mathrm{X}\right)^{2}\right\} /(\mathrm{n}-1)\right]^{[7,8,9,10,11]}$.

Table 1: 2-tailed t-distribution

\begin{tabular}{|c|c|c|c|c|c|c|c|c|c|c|}
\hline & & \multicolumn{2}{|c|}{ Zinc } & & \multicolumn{2}{|c|}{ Copper } & & \multicolumn{2}{|c|}{ Lead } & \\
\hline $\mathbf{N}$ & pH & $\mathbf{X i}$ & $\mathbf{X i - X}$ & $\mu \mathbf{H}_{0}$ & $\mathbf{X i}$ & $\mathbf{X i}-\mathbf{X}$ & $\mu \mathbf{H}_{0}$ & $\mathbf{X i}$ & $\mathbf{X i}-\mathbf{X}$ & $\mu \mathrm{H}_{0}$ \\
\hline 1 & 2 & 15 & -39.14 & 75 & 32 & -31.43 & 86 & 23 & -35.00 & 79 \\
\hline 2 & 3 & 30 & -24.14 & 75 & 45 & 18.43 & 86 & 45 & -13.00 & 79 \\
\hline 3 & 4 & 63 & 8.86 & 75 & 65 & 1.57 & 86 & 68 & 10.00 & 79 \\
\hline 4 & 5 & 75 & 20.86 & 75 & 86 & 22.57 & 86 & 79 & 21.00 & 79 \\
\hline 5 & 6 & 72 & 17.86 & 75 & 80 & 16.57 & 86 & 72 & 14.00 & 79 \\
\hline 6 & 7 & 67 & 12.86 & 75 & 72 & 8.57 & 86 & 63 & 5.00 & 79 \\
\hline 7 & 8 & 57 & 2.86 & 75 & 64 & 0.57 & 86 & 56 & -2.00 & 79 \\
\hline $\mathrm{X}$ & & 54.14 & & & 63.43 & & & 58.00 & & \\
\hline$\sigma_{\mathrm{s}}$ & & \multicolumn{3}{|c|}{22.81} & \multicolumn{3}{|c|}{19.10} & \multicolumn{3}{|c|}{18.97} \\
\hline d.f. & & \multicolumn{3}{|c|}{6} & \multicolumn{3}{|c|}{6} & \multicolumn{3}{|c|}{6} \\
\hline tobs & & \multicolumn{3}{|c|}{-2.420} & \multicolumn{3}{|c|}{-1.603} & \multicolumn{3}{|c|}{-2.371} \\
\hline tab & & \multicolumn{3}{|c|}{-2.447} & \multicolumn{3}{|c|}{-2.447} & \multicolumn{3}{|c|}{-2.447} \\
\hline
\end{tabular}

Calculations showed for a sample size of 7 , the standard deviation $\sigma_{\mathrm{s}}$ was 22.81, 19.10 and 18.97 for zinc, copper and lead respectively. $t_{\text {observed }}$ was $-2.420,-1.603$ and -2.371 for $\mathrm{Zn}$ II, $\mathrm{Cu}$ II and $\mathrm{Pb}$ II respectively. Whereas $\mathrm{t}_{\text {tabulated }}$ was 2.447 for 2-tailed t-distribution at $5 \%$ level of significance ${ }^{[12]}$. $t_{\text {observed }}<t_{\text {tabulated }}$ indicated that the observed values of $t$ lie within the accepted region of the probability chart. Hence, the null hypothesis is accepted.
2. Hypothesis testing to judge the time required to attain equilibrium: One-tailed t-test within 5\% level of significance was used for the testing the equilibrium time. $\mathrm{H}_{\mathrm{o}}: \mu \mathrm{H}_{\mathrm{o}}=$ Contact time to reach equilibrium (60 mins for $\mathrm{Zn}$ II, 120 mins for $\mathrm{Cu}$ II and 80 mins for $\mathrm{Pb}$ II) Alternate hypothesis $\mathrm{H}_{\mathrm{a}}>\mu \mathrm{H}_{\mathrm{o}}$.

Table 2: 1-tailed t-distribution

\begin{tabular}{|c|c|c|c|c|c|c|c|c|c|c|}
\hline & & \multicolumn{2}{|c|}{ Zinc } & \multicolumn{2}{c|}{ Copper } & \multicolumn{3}{|c|}{ Lead } & $\mathbf{X i - \mathbf { X }}$ & $\boldsymbol{\mu H}_{\mathbf{0}}$ \\
\hline $\mathbf{n}$ & Time (min) & $\mathbf{X i}$ & $\mathbf{X i - \mathbf { X }}$ & $\boldsymbol{\mu H}_{\mathbf{0}}$ & $\mathbf{X i}$ & $\mathbf{X i -} \mathbf{X}$ & $\boldsymbol{\mu} \mathbf{H}_{\mathbf{o}}$ & $\mathbf{X i}$ & $\mathbf{X i}$ \\
\hline 1 & 10 & 24 & -43.08 & 60 & 32 & -35.42 & 120 & 36 & -31.25 & 80 \\
\hline 2 & 20 & 50 & -17.08 & 60 & 40 & -27.42 & 120 & 45 & -22.25 & 80 \\
\hline 3 & 30 & 63 & -4.08 & 60 & 48 & -19.42 & 120 & 52 & -15.25 & 80 \\
\hline 4 & 40 & 70 & 2.912 & 60 & 58 & -9.42 & 120 & 60 & -7.25 & 80 \\
\hline 5 & 50 & 73 & 5.92 & 60 & 66 & -1.42 & 120 & 68 & 0.75 & 80 \\
\hline
\end{tabular}




\begin{tabular}{|c|c|c|c|c|c|c|c|c|c|c|}
\hline 6 & 60 & 75 & 7.92 & 60 & 72 & 4.58 & 120 & 74 & 6.75 & 80 \\
\hline 7 & 70 & 75 & 7.92 & 60 & 76 & 8.58 & 120 & 77 & 9.75 & 80 \\
\hline 8 & 80 & 75 & 7.92 & 60 & 80 & 12.58 & 120 & 79 & 11.75 & 80 \\
\hline 9 & 90 & 75 & 7.92 & 60 & 82 & 14.58 & 120 & 79 & 11.75 & 80 \\
\hline 10 & 100 & 75 & 7.92 & 60 & 84 & 16.58 & 120 & 79 & 11.75 & 80 \\
\hline 11 & 110 & 75 & 7.92 & 60 & 85 & 17.58 & 120 & 79 & 11.75 & 80 \\
\hline 12 & 120 & 75 & 7.92 & 60 & 86 & 18.58 & 120 & 79 & 11.75 & 80 \\
\hline $\bar{X}$ & & 67.08 & & & 67.41 & & & 67.25 & 11.75 & 80 \\
\hline$\sigma_{\mathrm{s}}$ & & \multicolumn{3}{|c|}{15.51} & \multicolumn{3}{|c|}{18.75} & \multicolumn{3}{|c|}{15.34} \\
\hline d.f.. & & \multicolumn{3}{|c|}{11} & \multicolumn{3}{|c|}{11} & \multicolumn{3}{|c|}{11} \\
\hline tobs & & \multicolumn{3}{|c|}{1.58} & \multicolumn{3}{|c|}{-9.71} & \multicolumn{3}{|c|}{-2.88} \\
\hline $\mathrm{t}_{\mathrm{tab}}$ & & \multicolumn{3}{|c|}{1.796} & \multicolumn{3}{|c|}{1.796} & \multicolumn{3}{|c|}{1.796} \\
\hline
\end{tabular}

$\mathrm{Xi}=$ Quantity of metal ions removed from samples of initial metal ions concentration $100 \mathrm{mg} / \mathrm{l}$ for 2 hours. Degrees of freedom $=$ d.f. $=\mathrm{n}-1=11$

Average value of $\mathrm{X}=\mathrm{X}=\Sigma \mathrm{X}_{\mathrm{i}} / \mathrm{n}$ and Standard deviation $=\sigma_{\mathrm{s}}$ $=\sqrt{ }\left[\left\{\Sigma\left(\mathrm{X}_{\mathrm{i}}-\mathrm{X}\right)^{2}\right\} /(\mathrm{n}-1)\right]^{[7,8,9,10,11]}$.

Calculations (Table 2) showed the standard deviation $\sigma_{\mathrm{s}}$ was 15.51, 18.75 and 15.34 for $\mathrm{Zn} \mathrm{II,} \mathrm{Cu}$ II and $\mathrm{Pb}$ II respectively., $\mathrm{t}_{\text {observed }}$ was $1.58,-9.71$ and -2.88 for respectively, whereas the $t_{\text {tab }}=1.796$ for 1 -tailed $t$-test for 11 degrees of freedom ${ }^{[12]}$. $t_{\text {observed }}<t_{\text {tabulated }}$ indicated that the observed values of $t$ lie within the accepted region of the probability chart. Hence, the null hypothesis was accepted.

\section{Hypothesis testing to test the equality of variance of two n-populations was done with F-test.}

$\mathrm{H}_{\mathrm{o}}: \mu_{\mathrm{Ho}}=$ Variances of two populations of different concentrations (100 mg/L and $50 \mathrm{mg} / \mathrm{L})$ of $\mathrm{Zn} \mathrm{II,} \mathrm{Cu} \mathrm{II} \mathrm{and}$ $\mathrm{Pb}$ II are same i.e. $\sigma_{\mathrm{p} 1}{ }^{2}=\sigma_{\mathrm{p} 2}{ }^{2}$

$\mathrm{H}_{\mathrm{a}}: \sigma_{\mathrm{p} 1}{ }^{2} \neq \sigma_{\mathrm{p} 2}{ }^{2}$

For F-test, $\mathrm{F}=\left(\sigma_{\mathrm{s} 1}{ }^{2}, \sigma_{\mathrm{s} 2}{ }^{2}\right)$ or $\left(\sigma_{\mathrm{s} 2}{ }^{2}, \sigma_{\mathrm{s} 1}{ }^{2}\right)=\mathrm{F}_{\text {observed }}, \mathrm{F}$ is always taken $>1$.

Table 3: F- distribution

Sample 1: $100 \mathrm{mg} / \mathrm{L}$

\begin{tabular}{|c|c|c|c|c|c|c|c|c|c|c|}
\hline \multirow[b]{2}{*}{$\mathbf{n}$} & \multirow[b]{2}{*}{ pH } & \multicolumn{2}{|c|}{ Zinc } & \multirow[b]{2}{*}{$\mu \mathbf{H}_{\mathbf{o}}$} & \multicolumn{2}{|c|}{ Copper } & \multirow[b]{2}{*}{$\mu \mathbf{H}_{\mathbf{o}}$} & \multicolumn{2}{|c|}{ Lead } & \multirow[b]{2}{*}{$\mu \mathbf{H}_{\mathbf{o}}$} \\
\hline & & $\mathbf{X}_{\mathbf{i} 1}$ & $\mathbf{X}_{\mathrm{i} 1}-\mathbf{X}_{1}$ & & $\mathbf{X}_{\mathbf{i 1}}$ & $\mathbf{X}_{\mathbf{i 1}-\mathbf{X}_{1}}$ & & $\mathbf{X}_{\mathbf{i} 1}$ & $\mathbf{X}_{\mathbf{i 1}-\mathbf{X}_{1}}$ & \\
\hline 1 & 2 & 15 & -39.14 & 75 & 32 & -31.43 & 86 & 23 & -35.00 & 79 \\
\hline 2 & 3 & 30 & -24.14 & 75 & 45 & 18.43 & 86 & 45 & -13.00 & 79 \\
\hline 3 & 4 & 63 & 8.86 & 75 & 65 & 1.57 & 86 & 68 & 10.00 & 79 \\
\hline 4 & 5 & 75 & 20.86 & 75 & 86 & 22.57 & 86 & 79 & 21.00 & 79 \\
\hline 5 & 6 & 72 & 17.86 & 75 & 80 & 16.57 & 86 & 72 & 14.00 & 79 \\
\hline 6 & 7 & 67 & 12.86 & 75 & 72 & 8.57 & 86 & 63 & 5.00 & 79 \\
\hline 7 & 8 & 57 & 2.86 & 75 & 64 & 0.57 & 86 & 56 & -2.00 & 79 \\
\hline $\mathrm{X}$ & & 54.14 & & & 63.43 & & & 58.00 & & \\
\hline$\overline{\sigma_{\mathrm{s} 1}{ }^{2}}$ & & & 520.14 & & & 364.62 & & & 360.00 & \\
\hline
\end{tabular}

Sample 2: $50 \mathrm{mg} / \mathrm{L}$

\begin{tabular}{|c|c|c|c|c|c|c|c|c|c|c|}
\hline \multirow[b]{2}{*}{$\mathrm{n}$} & \multirow[b]{2}{*}{ pH } & \multicolumn{2}{|c|}{ Zinc } & \multirow[b]{2}{*}{$\mu \mathbf{H}_{0}$} & \multicolumn{2}{|c|}{ Copper } & \multirow[b]{2}{*}{$\mu \mathbf{H}_{\mathbf{0}}$} & \multicolumn{2}{|c|}{ Lead } & \multirow[b]{2}{*}{$\mu \mathbf{H}_{0}$} \\
\hline & & $\mathbf{X}_{\mathrm{i} 2}$ & $\mathbf{X}_{\mathrm{i} 2}-\mathbf{X}_{2}$ & & $\mathbf{X}_{\mathrm{i} 2}$ & $\mathbf{X}_{\mathrm{i} 2-\mathbf{X}_{2}}$ & & $\mathbf{X}_{\mathrm{i} 2}$ & $\mathbf{X}_{\mathrm{i} 2-}-\mathbf{X}_{2}$ & \\
\hline 1 & 2 & 24 & -36.71 & 75 & 38 & -30.00 & 86 & 29 & -34.86 & 79 \\
\hline 2 & 3 & 42 & -18.71 & 75 & 49 & -19.00 & 86 & 51 & 12.86 & 79 \\
\hline 3 & 4 & 69 & 8.28 & 75 & 72 & 4.00 & 86 & 74 & 10.14 & 79 \\
\hline 4 & 5 & 82 & 21.28 & 75 & 89 & 21.00 & 86 & 84 & 20.14 & 79 \\
\hline 5 & 6 & 76 & 15.28 & 75 & 83 & 15.00 & 86 & 78 & 14.14 & 79 \\
\hline 6 & 7 & 70 & 9.28 & 75 & 75 & 7.00 & 86 & 66 & 2.14 & 79 \\
\hline 7 & 8 & 62 & 1.28 & 75 & 70 & 2.00 & 86 & 65 & 1.14 & 79 \\
\hline $\mathrm{X}$ & & 60.71 & & & 68.00 & & & 63.86 & & \\
\hline$\sigma_{\mathrm{s} 2}{ }^{2}$ & & & 423.57 & & & 332.67 & & & 349.14 & \\
\hline $\mathrm{F}_{\text {obs }}$ & & & 1.23 & & & 1.20 & & & 1.06 & \\
\hline $\mathrm{F}_{\mathrm{tab}}$ & & & 4.28 & & & $\begin{array}{l}4.28 \\
\end{array}$ & & & 4.28 & \\
\hline
\end{tabular}

$\mathrm{Xi}=\%$ removal of metal ions from the contaminated samples and Degrees of freedom $=$ d.f. $=n-1$

Average value of $\mathrm{X}=\mathrm{X}=\Sigma \mathrm{X}_{\mathrm{i}} / \mathrm{n}$ and Standard deviation $=\sigma_{\mathrm{s}}$ $=\sqrt{ }\left[\left\{\Sigma\left(\mathrm{X}_{\mathrm{i}}-\mathrm{X}\right)^{2}\right\} /(\mathrm{n}-1)\right] .{ }^{[7,8,9,10,11]}$.

Calculations (Table 3) showed that the variances $\sigma_{\mathrm{s} 1}{ }^{2}$ and $\sigma_{\mathrm{s} 2}{ }^{2}$ are $520.14 \& 423.57$ for Zn II, $364.62 \& 332.67$ for $\mathrm{Cu}$

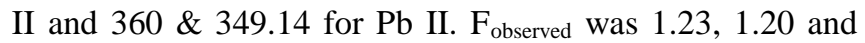
1.06 for $\mathrm{Zn}$ II, $\mathrm{Cu}$ II and $\mathrm{Pb}$ II respectively. Whereas $\mathrm{F}_{\text {tabulated }}$ $=4.28^{[12]}$. $\mathrm{F}_{\text {observed }}<\mathrm{F}_{\text {tabulated }}$ indicated that the observed values of $\mathrm{F}$ lie within the accepted region of the probability chart. Hence for all the three ions, the null hypothesis, was accepted.

4. Hypothesis testing to test the effectiveness of the experiment in removing heavy metal ions was done with $\chi^{2}$-test.

Experiments were conducted for values of $\mathrm{pH}$ varying from 2 to 8 , metal ion concentration in the range 10 to $100 \mathrm{mg} / \mathrm{L}$ and adsorbent dose 1 to $10 \mathrm{~g} / \mathrm{L}$. Metal ion removal frequencies were observed for $\%$ removal between groups 0 $20 \%$ (1), $20-40 \%$ (2), 40-60\% (3), 60-80\% (4) and 80-100\% (5) for zinc, copper and lead ions. Since the observed frequencies in groups 1 and 5 i.e. \% removal in the range 0 - 
$20 \%$ and $80-100 \%$ were less than 10 , they were combined with groups 2 and 4 respectively to make the frequencies greater than 10. The values of expected frequencies for each group were equal and 12 each.

$\mathrm{H}_{\mathrm{o}}: \mu_{\mathrm{Ho}}=$ Adsorption is an effective technique for removal of $\mathrm{Zn} \mathrm{II,} \mathrm{Cu}$ II and $\mathrm{Pb}$ II
$\mathrm{H}_{\mathrm{a}}$ : Adsorption is not an effective technique for removal of $\mathrm{Zn}$ II, $\mathrm{Cu}$ II and $\mathrm{Pb}$ II For chi-square test

$\chi^{2}=\Sigma\left\{\left(\mathrm{O}_{\mathrm{i}}-\mathrm{E}_{\mathrm{i}}\right)^{2} / \mathrm{E}_{\mathrm{i}}\right\},[7,8,9,10,11]$.

$\mathrm{O}_{\mathrm{i}}=$ Observed frequencies of metal ion removal in the $\mathrm{i}^{\text {th }}$ row.

$\mathrm{E}_{\mathrm{i}=}$ Expected frequencies of metal ion removal in the $\mathrm{i}^{\text {th }}$ row .

Table 4: Chi Square distribution to test the effectiveness of the experiment

\begin{tabular}{|c|c|c|c|c|c|c|c|c|c|c|}
\hline S. No. & Groups & & Zinc & Copper & Lead & Rearranging groups to make frequencies $>\mathbf{1 0}$ & & Zinc & Copper & Lead \\
\hline $\mathbf{n}$ & \% removal & $\mathbf{E}_{\mathbf{i}}$ & $\mathbf{O}_{\mathbf{i}}$ & $\mathbf{O}_{\mathbf{i}}$ & $\overline{\mathbf{O}_{\mathrm{i}}}$ & $\mathbf{n}$ & $\mathbf{E}_{\mathbf{i}}$ & $\overline{\mathbf{O}_{\mathbf{i}}}$ & $\mathbf{O}_{\mathrm{i}}$ & $\overline{\mathbf{O}_{\mathrm{i}}}$ \\
\hline 1 & $0-20 \%$ & 12 & 4 & 7 & 3 & $1 \& 2$ & 24 & 19 & 19 & 16 \\
\hline 2 & $20-40 \%$ & 12 & 15 & 12 & 13 & 3 & 12 & 18 & 22 & 17 \\
\hline 3 & $40-60 \%$ & 12 & 18 & 22 & 17 & $4 \& 5$ & 24 & 23 & 19 & 27 \\
\hline 4 & $60-80 \%$ & 12 & 17 & 16 & 18 & & & & & \\
\hline 5 & $80-100 \%$ & 12 & 6 & 3 & 9 & & & & & \\
\hline & d.f. & & & & & & & 4 & 4 & 4 \\
\hline & $\chi_{\text {obs }}^{2}$ & & & & & & & 3.583 & 2.417 & 8.625 \\
\hline & $\chi^{2}$ tab & & & & & & & 9.488 & 9.488 & 9.488 \\
\hline
\end{tabular}

Calculations (Table 4 ) showed that $\chi 2_{\text {observed }}=3.58,2.42$ and 8.625 for $\mathrm{Zn} \mathrm{II}, \mathrm{Cu}$ II and $\mathrm{Pb}$ II respectively. Whereas

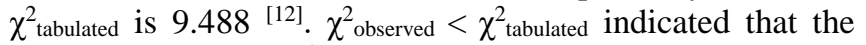
observed values of $\chi^{2}$ lie within the accepted region of the probability chart. Hence null hypothesis was accepted.
5. Analysis of variance (ANOVA) we compared adsorption capacities of mango tree leaves for three different heavy metal ions for varying values of adsorbent dose (Table 5).

Table 5: Anova

Here samples are \% removal from $100 \mathrm{ppm}$ solutions of $\mathrm{Zn} \mathrm{II,} \mathrm{Cu}$ II and $\mathrm{Pb}$ II

\begin{tabular}{|c|c|c|c|c|}
\hline \multirow{2}{*}{$\mathbf{n}$} & \multirow{2}{*}{ Adsorbent dose, g/L } & \multicolumn{3}{|c|}{ \% removal from 100 ppm concentration } \\
\cline { 3 - 5 } & & $\mathbf{C u}$ & $\mathbf{Z n}$ & $\mathbf{P b}$ \\
\hline 1 & 2 & 20 & 25 & 22 \\
\hline 2 & 4 & 40 & 40 & 42 \\
\hline 3 & 6 & 58 & 64 & 56 \\
\hline 4 & 8 & 72 & 75 & 71 \\
\hline 5 & 10 & 90 & 87 & 85 \\
\hline Sum & & 280 & 291 & 276 \\
\hline Mean $\overline{\mathrm{a}}$ & & 56 & 58.2 & 55.2 \\
\hline
\end{tabular}

\begin{tabular}{|c|c|c|c|c|c|c|}
\hline $\mathbf{n}$ & \% removal For Cu (a) & $\left(\mathbf{a}_{1}-\overline{\mathbf{a}}_{1}\right)^{\mathbf{2}}$ & \% removal For Zn $\left(\mathbf{a}_{2}\right)$ & $\left(\mathbf{a}_{2}-\overline{\mathbf{a}}_{2}\right)^{\mathbf{2}}$ & \% removal For Pb $\left(\mathbf{a}_{3}\right)$ & $\left(\mathbf{a}_{3}-\overline{\mathbf{a}}_{3}\right)^{\mathbf{2}}$ \\
\hline 1 & 20 & 1296 & 25 & 1102.24 & 22 & 1102.24 \\
\hline 2 & 40 & 256 & 40 & 331.24 & 42 & 174.25 \\
\hline 3 & 58 & 4 & 64 & 33.64 & 56 & 0.64 \\
\hline 4 & 72 & 1156 & 75 & 282.24 & 71 & 249.64 \\
\hline 5 & 90 & 2968 & 291 & 2578.8 & 276 & 888.04 \\
\hline Sum & 280 & & 58.2 & & 55.2 & 2414.8 \\
\hline Mean $\bar{a}$ & 56 & \multicolumn{5}{c}{} \\
\hline
\end{tabular}

Sum of squares within $(\mathrm{SSW})=\left(\mathbf{a}_{1}-\overline{\mathbf{a}}_{1}\right)^{2}+\left(\mathbf{a}_{2}-\overline{\mathbf{a}}_{2}\right)^{2}+\left(\mathbf{a}_{3}-\overline{\mathbf{a}}_{3}\right)^{2}=7961.6$

\begin{tabular}{|c|c|c|}
\hline $\mathbf{n}$ & Total observations $\mathbf{a}_{\mathbf{i}}$ & $\left(\mathbf{a}_{\mathbf{i}}-\overline{\mathbf{a}}_{\mathbf{i}}\right)^{\mathbf{2}}$ \\
\hline 1 & 20 & 1329.82 \\
\hline 2 & 40 & 271.15 \\
\hline 3 & 58 & 2.35 \\
\hline 4 & 72 & 241.28 \\
\hline 5 & 90 & 1124.48 \\
\hline 6 & 25 & 999.15 \\
\hline 7 & 40 & 271.15 \\
\hline 8 & 64 & 56.75 \\
\hline 9 & 75 & 343.48 \\
\hline 10 & 87 & 932.28 \\
\hline 11 & 22 & 1187.95 \\
\hline 12 & 42 & 209.28 \\
\hline 13 & 56 & 0.22 \\
\hline 14 & 71 & 211.22 \\
\hline 15 & 85 & 814.15 \\
\hline Sum & 847 & \\
\hline Mean $\overline{\mathrm{a}}_{\mathrm{i}}$ & 56.47 & 7985.73 \\
\hline
\end{tabular}


Mean of sample means $\overline{\mathrm{a}}=\left(\overline{\mathrm{a}}_{1}+\overline{\mathrm{a}}_{2}+\overline{\mathrm{a}}_{3}\right) / 3=56.47$ and Sum of squares within $(\mathrm{SSW})=7961.6$

Sum of squares total $(\mathrm{SST})=7985.73$ and Sum of squares between $(\mathrm{SSB})=24.13$

Degrees of freedom: d.f for SSB $=2$, d.f. for $\mathrm{SSW}=12$

MS between $=$ SSB $/$ d.f for SSB $=12.07$ and MS within $=$ $\mathrm{SSW} /$ d.f for SSW $=663.47$

$\mathrm{F}_{\mathrm{cal}}=\mathrm{MS}$ between/ MS within $=0.018$ and $\mathrm{F}_{\mathrm{tab}}=19.41$

$F_{\text {tab }}<F_{\text {cal }}$, Null hypothesis i.e. the mean of samples from 3 different populations are same is accepted.

$\mathrm{H}_{\mathrm{o}}=$ Samples are drawn from three populations having the same mean

$\mathrm{H}_{\mathrm{a}}=$ Samples are drawn from three populations which do not have same mean

F-ratio (Eq. 5) calculated $\mathrm{F}_{\text {observed }}=0.018$ and tabulated $F_{\text {tabulated }}=19.41$ for $(2,12)$ degrees of freedom ${ }^{[13,14]}$. Since

$F_{\text {observed }}<F_{\text {tabulated, null hypothesis was accepted. }}$

\section{Conclusions and Recommendations}

In the above study, the experimental data was obtained for the removal of $\mathrm{Zn} \mathrm{II,} \mathrm{Cu}$ II and $\mathrm{Pb}$ II ions from the contaminated water samples. The null hypotheses were defined and experimental data was tested at $5 \%$ level of significance each. Calculated values of $\mathrm{z}$, t-test, $\chi^{2}$-test, Ftest and ANOVA were compared with tabulated values available in literature and were found to be within accepted regions of the probability charts. Hence the null hypotheses were accepted, validating the experimental data statistically. Paired t-test to compare two related samples, statistical tests for correlation coefficients and adsorption isotherm are recommended for future studies.

\section{References}

1. Dabrowski A Adsorption-from theory to practice. Adv. Colloid Interface Sci 2001;93:135-224.

2. Ferhan C, Ozgur A. Activated Carbon for Water and Wastewater Treatment: Integration of Adsorption and Biological Treatment. $1^{\text {st }}$ ed. WILEY-VCH Verlag GmbH \& Co. KGaA, Weinheim, 2011.

3. Goel PK. Water pollution, Causes, Effects and Control, Revised $2^{\text {nd }}$ ed., New Age International Publishers, N. Delhi, 2006.

4. Cafer S, Omer S, Ahin MM. Applications on agricultural and forest waste adsorbents for the removal of lead (II) from contaminated waters. International Journal of Environmental Science and Technology. 2012;9:379-394.

5. Conrad K, Hansen HCB. Sorption of zinc and lead on coir. Bioresour. Technol 2007;98:89-97.

6. Wong KK, Lee K, Low KS, Haron MJ. Removal of $\mathrm{Cu}$ and $\mathrm{Pb}$ by tartaric acid modified rice husk from aqueous solutions. Chemosphere 2003;50:23-28.

7. Kaushal A, Singh SK. Application of statistical tools and hypothesis testing of adsorption data obtained for removal of heavy metals from aqueous solutions. International Journal of Advanced Research and Innovation 2016;4:82-84.

8. Bowley AL. Elements of Statistics, $6^{\text {th }}$ ed, P.S. King and Staples Ltd., London 1937.

9. Anderson TW. An Introduction to Multivariate Analysis, John Wiley \& Sons, New York, 1958.

10. Chance WA. Statistical Methods for Decision Making, D.B. Taraporevala Sons \& Co. Pvt Ltd., Bombay 1975.
11. Kothari CR. Quantitative techniques, $2^{\text {nd }}$ ed., Vikas Publishing House Pvt. Limited, N. Delhi 1984.

12. Kothari CR. Research Methodology: Methods \& Techniques, New Age International (P) Limited, Publishers, New Delhi 2005.

13. Kaushal A, Singh SK. Removal of Zn (II) from aqueous solutions using agro-based adsorbents. Imperial Journal of Interdisciplinary Research 2016;2:1215-1218.

14. Kaushal A, Singh SK. Critical analysis of adsorption data statistically, Appl. Water Sci 2017. DOI 10.1007/s13201-016-0466-4. 